\title{
When to re-dose regadenoson?
}

\author{
Gregory S. Thomas, MD, MPH, MASNC, ${ }^{\mathrm{a}, \mathrm{b}}$ Aaron F. Jolly, MD,, and \\ Michael Safani, PharmD ${ }^{a, c, d}$ \\ a MemorialCare Heart \& Vascular Institute, Long Beach Memorial Medical Center, Long Beach, CA \\ b Division of Cardiology, University of California, Irvine, CA \\ c Department of Pharmacy Services, Long Beach Memorial, Long Beach, CA \\ d School of Pharmacy, University of California, San Francisco, CA
}

Received Dec 1, 2015; accepted Dec 1, 2015

doi: $10.1007 / \mathrm{s} 12350-015-0376-0$

\section{See related article, pp. 57-65}

Since FDA approval in 2008, regadenoson, an A2A adenosine receptor agonist, has become the most commonly used pharmacological stress testing agent in the U.S. ${ }^{1}$ In this issue of the Journal, Townsend et $\mathrm{al}^{2}$ address the important question of how to manage redosing of regadenoson if it were to become necessary. This information would be helpful, for example, if the FDA approved $0.4 \mathrm{mg}(400 \mu \mathrm{g})$ dose of regadenoson were administered intravenously (IV) but the radiotracer became inadvertently unavailable or in the case of an infiltrated IV line resulting in the subcutaneous administration of regadenoson.

Townsend et $\mathrm{al}^{2}$ evaluated the pharmacokinetics (the study of the time course of the drug's absorption, distribution, metabolism, and excretion) and pharmacodynamics (the study of the biochemical and physiological effects of a drug on the body) of different doses of regadenoson administered every 10 minutes (min). To do so, they randomized 36 healthy men and women, mean age 38 years, who were not on any medications, to receive either 3 separate doses of $0.1 \mathrm{mg}$ 10 minutes apart, 3 doses of $0.2 \mathrm{mg} 10$ minutes apart, 2 doses of $0.4 \mathrm{mg} 10$ minutes apart or 2 or 3 doses of placebo 10 minutes apart. In addition to measuring

Reprint requests: Gregory S. Thomas, MD, MPH, MASNC, MemorialCare Heart \& Vascular Institute, Long Beach Memorial Medical Center, 2801 Atlantic Ave, Long Beach, CA 90806; gthomas1@ memorialcare.org

J Nucl Cardiol 2017;24:66-8.

$1071-3581 / \$ 34.00$

Copyright (C) 2015 American Society of Nuclear Cardiology. plasma concentrations of regadenoson, they studied the pharmacodynamic effect on blood pressure and heart rate as primary endpoints.

Work by Lieu et $\mathrm{al}^{3}$ evaluated the pharmacodynamic effect of escalating doses of regadenoson on coronary velocity using a coronary Doppler flow wire. They found that regadenoson doses of $0.1 \mathrm{mg}, 0.3$ and $0.4 \mathrm{mg}$ increased peak velocity above baseline by $3.0 \pm$ 0.6 (SD), $3.4 \pm 0.8$, and $3.1 \pm 0.5$ times, respectively. As flow increases linearly with velocity, by the formula [Flow $=\pi r^{2}$ (average velocity)(0.5) $\times 60$ ] with $r$ equal to vessel radius, peak myocardial blood flow would thus increase to a similar degree with either 0.1 or $0.4 \mathrm{mg}$ of regadenoson. However, the $0.4 \mathrm{mg}$ dose was selected for use with MPI as it produced a sustained velocity 2.5 times above baseline for 2.3 minutes compared to $<2$ minutes for smaller doses. ${ }^{3,4}$

Townsend et $\mathrm{al}^{2}$ found $0.4 \mathrm{mg}$ of regadenoson to result in mean plasma concentrations of $\approx 18$ and $\approx 9$ $\mathrm{ng} \cdot \mathrm{mL}^{-1}$ at 3 and $9 \mathrm{~min}$, respectively. Given earlier findings of Lieu et $\mathrm{al}^{3}$ that coronary velocity remains $\geq 2$ times baseline for a mean of 9 minutes, a concentration of $9 \mathrm{ng} \cdot \mathrm{mL}^{-1}$ would correlate with a $\approx$ twofold increase in velocity.

Using the $0.1 \mathrm{mg}$ dose, which Lieu et $\mathrm{al}^{3}$ found to increase coronary velocity threefold, Townsend et $\mathrm{al}^{2}$ found $0.1 \mathrm{mg}$ to result in a mean concentration of $\approx 5$ $\mathrm{ng} \cdot \mathrm{mL}^{-1}$ measured 3 minutes post dosing. This was the first time of measurement in their study. Correlating this dose with coronary velocity in the study of Lieu et $\mathrm{al}^{3}$ is difficult, as coronary velocity had decreased to $<2$ times baseline by 3 minutes with this dose. Nonetheless, the coronary velocity curves Lieu et $\mathrm{al}^{3}$ observed are consistent with a significant impact on coronary velocity remaining at 3 minutes in relation to a plasma concentration of $\approx 5 \mathrm{ng} \cdot \mathrm{mL}^{-1}$.

Thus, clinically re-dosing $0.4 \mathrm{mg}$ of IV regadenoson 10 minute after an initial $0.4 \mathrm{mg}$ IV dose as performed in 
the study of Townsend et $\mathrm{al}^{2}$ would be re-administering regadenoson at a time when the initial dose still has a considerable pharmacodynamic effect on coronary velocity and flow.

As well, as Townsend et $\mathrm{al}^{2}$ demonstrate in Figure 4, a 10 minutes re-dosing interval resulted in a concentration of $\approx 24 \mathrm{ng} \cdot \mathrm{mL}^{-1}$ at 3 minute following the second dose of $0.4 \mathrm{mg}$ administered at 10 minutes compared to $\approx 18 \mathrm{ng} \cdot \mathrm{mL}^{-1} 3$ minutes after the first dose. As a single dose of $0.4 \mathrm{mg}$ is adequate to achieve the necessary pharmacodynamic effect at a concentration of $\approx 18 \mathrm{ng} \cdot \mathrm{mL}^{-1}$, a higher concentration of $\approx 24$ $\mathrm{ng} \cdot \mathrm{mL}^{-1}$ is unnecessary. Consistent with this concern, Hendel et $\mathrm{al}^{5}$ observed more adverse events during their dose ranging study when $0.5 \mathrm{mg}$ of regadenoson was used compared to $0.4 \mathrm{mg}$.

While the vasodilatory effects of regadenoson are understood to be a direct effect on the A2A receptor in the vessel wall, the heart rate increase is most consistent with an indirect effect, mediated through stimulation of the $\mathrm{A} 2 \mathrm{~A}$ receptors in the carotid body resulting in an increase in plasma norepinephrine. ${ }^{6}$ This sympathetic stimulatory effect is observed with adenosine and dipyridamole, as well. ${ }^{7}$ This presumably causes the brief "'mini-panic attack' feeling that patients often experience beginning 30-90 seconds after administration of regadenoson or adenosine. As observed in other studies, ${ }^{3,8}$ heart rate increases with escalating doses of regadenoson, although the incremental increase is not directly proportional to dose. Figure 3 and Appendix 2 of Townsend et $\mathrm{al}^{2}$ demonstrate an additional $5 \mathrm{bpm}$ heart rate increase with a second dose of $0.4 \mathrm{mg}$ of regadenoson over and above the $45 \mathrm{bpm}$ heart rate increase observed with the first dose.

If 10 minutes is too early to re-dose, when should re-dosing occur? A reasonable re-dosing interval can be considered by an analysis of regadenoson pharmacokinetics and pharmacodynamics. In 2 contributions, Gordi et $\mathrm{al}^{8,9}$ found regadenoson's pharmacokinetics best described by a 3-compartment model with linear clearance (whereby drug removal is proportional to time) and tri-phasic half-lives. The initial half-life of 2-4 minutes corresponds roughly to the drug's appearance in the vascular space and other tissues following IV injection and has a volume of distribution of $11.5 \mathrm{~L}$. The intermediate half-life of $\approx 30$ minutes corresponds roughly to distribution into other tissues with a volume of distribution of $59 \mathrm{~L}$. The combined duration of these 2 halflives over 4-5 half-lives appears to correspond to its loss of pharmacodynamic effects. Based on pharmacokinetic principles, 4-5 half-lives are required to eliminate 94$97 \%$ of a drug from its site of action. The terminal elimination half-life is $\approx 120$ minutes and reflects redistribution from tissue compartments into the vascular compartment, as well as loss of drug from the body via the renal system. ${ }^{8,10,11}$

The major elimination pathway is renal with $58 \%$ of the dose cleared by the kidneys both by glomerular filtration and tubular secretion. ${ }^{8}$ In patients with creatinine clearance $<80 \mathrm{~mL} \cdot \mathrm{min}^{-1}$, regadenoson's clearance decreases with a corresponding increase in plasma concentration and prolongation of the terminal half-life. ${ }^{9}$

Throughout the 3 distinct half-lives, regadenoson is distributed from the vascular compartment into various tissues and redistributed back, resulting in mean plasma concentrations of $>2$ and $>1 \mathrm{ng} \cdot \mathrm{mL}^{-1}$ at 1 and 2 hours following $0.4 \mathrm{mg}$ of regadenoson, respectively (estimates obtained from Figure 3 of Gordi et al). ${ }^{9}$ Townsend et $\mathrm{al}^{2}$ observed similar mean concentrations at 1 and 2 hours, $\approx 3$ and $\approx 2 \mathrm{ng} \cdot \mathrm{mL}^{-1}$, respectively, following 2 doses of $0.2 \mathrm{mg}$ of regadenoson 10 minutes apart (for a total of $0.4 \mathrm{mg}$ ). Assessing the effect on heart rate in 24 subjects 1 and 2 hours following $0.4 \mathrm{mg}$ of regadenoson, Gordi et $\mathrm{al}^{9}$ found 2 of the 24 subjects to have heart rates that remained $>10 \mathrm{bpm}$ above baseline at 1 hour. By 2 hours, heart rates in all subjects were within $10 \mathrm{bpm}$ of baseline.

Another consideration of re-dosing is the potential for tachyphylaxis. Desensitization of A2A receptors has been reported in experimental models. ${ }^{12-14}$ Trochu et $\mathrm{al}^{15}$ measured coronary blood flow in the dog model over 3 consecutive regadenoson injections $\left(1 \mathrm{mcg} \cdot \mathrm{kg}^{-1}\right.$, a relatively low dose) administered 5-10 minutes apart. Coronary blood flow $\left(\mathrm{mL} \cdot \mathrm{min}^{-1}\right)$ decreased with each successive dose, $229 \pm 14,218 \pm 13,192 \pm 14$. As this decrease did not reach significance, the authors interpreted the finding as not consistent with tachyphylaxis. The trend could be interpreted as a signal of tachyphylaxis, however. To our knowledge, tachyphylaxis has not been evaluated in humans with coronary flow measurements. In the study of Townsend et $\mathrm{al}^{2}$ there is also a signal of a tachyphylaxis effect as subjects described fewer adverse events with repeated doses of 0.2 and 0.4 $\mathrm{mg}$ of regadenoson. Alternatively, however, the decrease in adverse effects could have been secondary to familiarity with symptoms observed with regadenoson.

Given the pharmacodynamic effect on coronary vasodilation at relatively low plasma concentrations of regadenoson, the apparent lack of pharmacodynamic properties during the terminal half-life, the unknown potential of tachyphylaxis in humans and application of 4-5 half-lives, a reasonable re-dosing interval may be estimated. Using the sum of the initial and intermediate half-lives of 2-4 and 30 minutes, respectively, 4 and 5 half-lives would be approximately 132-165 minutes. Thus, a re-dosing interval of 150 minutes ( 2.5 hours) is recommended following an IV dose of $0.4 \mathrm{mg}$ of regadenoson. Estimating a re-dosing interval following 
subcutaneous administration of regadenoson is problematic as absorption would differ from IV administration, the route of administration studied by Townsend et al. ${ }^{2}$ A pharmacokinetic study evaluating subcutaneous administration of regadenoson is welcomed. Until such a study is performed, a re-dosing interval of 2.5 hours appears reasonable.

As regadenoson is predominately renally excreted and the pharmacokinetics of regadenoson in patients on dialysis have yet to be investigated and reported, further pharmacokinetic investigation is suggested prior to recommendations regarding a re-dosing interval in patients on dialysis.

Thanks are due to Townsend and his colleagues for their important contribution in this issue of the Journal. ${ }^{2}$ Another pharmacodynamic investigation opportunity is the intriguing potential of decreasing adverse effects with an injection time $>10$ seconds. Such a study would require measurement of coronary velocity to determine the specific timing of the increase in coronary flow when a longer injection time is used. This would allow a determination of optimal timing of radiotracer injection with a longer injection.

Lastly, as women experience more adverse events than men with all three generations of vasodilators, dipyridamole, ${ }^{16}$ adenosine, ${ }^{17,18}$ and regadenoson, ${ }^{19}$ separately investigating and reporting the pharmacokinetic and pharmacodynamic responses of regadenoson and future pharmacologic stress agents in women is recommended.

\section{Disclosure}

Gregory S. Thomas, MD, MPH is a scientific advisor and a member of the speakers bureau for Astellas Pharma US. The other authors have no disclosures.

\section{References}

1. Zoghbi GJ, Iskandrian AE. Selective adenosine agonists and myocardial perfusion imaging. J Nucl Cardiol 2012;19:126-41.

2. Townsend R, Rammelsberg D, Kowalsk D, Simmons N, Kitt TM. Safety and tolerability of intravenous regadenoson in healthy subjects: A randomized, repeat-dose placebo-controlled study. J Nucl Cardiol 2015. doi:10.1007/s12350-015-0327-9.

3. Lieu HD, Shryock JC, von Mering GO, Gordi T, Blackburn B, Olmsted AW, et al. Regadenoson, a selective A2A adenosine receptor agonist, causes dose-dependent increases in coronary blood flow velocity in humans. J Nucl Cardiol 2007;14:514-20.

4. Cerqueira MD. Advances of pharmacologic agents in imaging: New A2a receptor agonists. Curr Cardiol Rep 2006;8:119-22.
5. Hendel RC, Bateman TM, Cerqueira MD, Iskandrian AE, Leppo JA, Blackburn B, et al. Initial clinical experience with regadenoson, a novel selective A2A agonist for pharmacologic stress single-photon emission computed tomography myocardial perfusion imaging. J Am Coll Cardiol 2005;46:2069-75.

6. Dhalla AK, Wong MY, Wang WQ, Biaggioni I, Belardinelli L. Tachycardia caused by A2A adenosine receptor agonists is mediated by direct sympathoexcitation in awake rats. J Pharmacol Exp Ther 2006;316:695-702.

7. Engelstein ED, Lerman BB, Somers VK, Rea RF. Role of arterial chemoreceptors in mediating the effects of endogenous adenosine on sympathetic nerve activity. Circulation 1994;90:2919-26.

8. Gordi T, Frohna P, Sun HL, Wolff A, Belardinelli L, Lieu H. A population pharmacokinetic/pharmacodynamic analysis of regadenoson, an adenosine A2A-receptor agonist, in healthy male volunteers. Clin Pharmacokinet 2006;45:1201-12.

9. Gordi T, Blackburn B, Lieu H. Regadenoson pharmacokinetics and tolerability in subjects with impaired renal function. J Clin Pharmacol 2007;47:825-33.

10. Highlights of prescribing information. Lexiscan (regadenoson) injection for intravenous use. https://www.astellas.us/docs/lexiscan. pdf. Accessed 27 Nov 2015.

11. Bengalorkar GM, Bhuvana K, Sarala N, Kumar TN. Regadenoson. J Postgrad Med 2012;58:140-6.

12. Anand-Srivastava MB, Cantin M, Ballak M, Picard S. Desensitization of the stimulatory A2 adenosine receptor-adenylate cyclase system in vascular smooth muscle cells from rat aorta. Mol Cell Endocrinol 1989;62:273-9.

13. Ramkumar V, Olah ME, Jacobson KA, Stiles GL. Distinct pathways of desensitization of A1- and A2-adenosine receptors in DDT1 MF-2 cells. Mol Pharmacol 1991;40:639-47.

14. Makujina SR, Mustafa SJ. Adenosine-5'-uronamides rapidly desensitize the adenosine A2 receptor in coronary artery. J Cardiovasc Pharmacol 1993;22:506-9.

15. Trochu JN, Zhao G, Post H, Xu X, Belardinelli L, Belloni FL, et al. Selective A2A adenosine receptor agonist as a coronary vasodilator in conscious dogs: Potential for use in myocardial perfusion imaging. J Cardiovasc Pharmacol 2003;41:132-9.

16. Lette J, Bertrand C, Gossard D, Ruscito O, Cerino M, McNamara $\mathrm{D}$, et al. Long-term risk stratification with dipyridamole imaging. Am Heart J 1995;129:880-6.

17. Cerqueira MD, Verani MS, Schwaiger M, Heo J, Iskandrian AS. Safety profile of adenosine stress perfusion imaging: Results from the Adenoscan Multicenter Trial Registry. J Am Coll Cardiol 1994;23:384-9.

18. Thomas GS, Thompson RC, Miyamoto MI, Ip TK, Rice DL, Milikien D, et al. The RegEx trial: A randomized, double-blind, placebo- and active-controlled pilot study combining regadenoson, a selective $\mathrm{A}(2 \mathrm{~A})$ adenosine agonist, with low-level exercise, in patients undergoing myocardial perfusion imaging. J Nucl Cardiol 2009;16:63-72.

19. Cerqueira MD, Nguyen $P$, Staehr P, Underwood SR, Iskandrian AE, Investigators A-MT. Effects of age, gender, obesity, and diabetes on the efficacy and safety of the selective A2A agonist regadenoson versus adenosine in myocardial perfusion imaging integrated ADVANCE-MPI trial results. JACC Cardiovasc Imaging 2008;1:307-16. 